DOI: $10.1515 /$ rpp-2017-0040

Master of Technology Degree, Assistant Professor, SHRISH BAJPAI

Integral University

Address: Kursi Road, Lucknow, Uttar Pradesh, India E-mail: shrishbajpai@gmail.com

Bachelor of Technology Degree, SHAGIL AKHTAR

Integral University

Address: Kursi Road, Lucknow, Uttar Pradesh, India

E-mail: shagilakhtar@gmail.com

\title{
INDUSTRIAL ENGINEERING EDUCATION IN INDIA
}

\begin{abstract}
The industrial revolution can be termed as the catalyst of human growth. The establishment of various industries has been detrimental to the meteoric rise of any commodity, product or service across the world. Industries fuel the economy of countries and form the main constituent of their GDP. Industries not only generate the production of the market ready material but also generate the employment for the citizens of the country, which drives multiple factors of any country progress. In order to keep the industries thriving, we need commendable industrial engineers who have not only the skills of a technician but also as a manager to run the plant successful. Indian Government initiative "Make in India" to establish the industries in India, will not be successful without the capable Industrial Engineers. This paper focuses on the engineering education structure of India with regard to Industrial Engineering from diploma level to post doctoral level and assesses how our education system is incubating future industrial engineers. We have made some suggestions why this engineering discipline should be offered as a regular engineering discipline in India and highlighted the contribution of the Indian government to this discipline. We have given a brief view on the comparative status of industrial engineering with other countries and provided the suggestions to improve the industrial engineering education in India. Thus, Industrial Engineering plays a pivotal role in the field of engineering for the proper development of industries in any nation. Indian government's initiatives in laying the framework of the industries for those commodities, which India is purchasing from the other parts of the world since independence is praiseworthy. These production plants across the country will see the advantage in the manufacturing and production engineering. Present scenario of industrial engineering education seems in its premature stages in India. With a mere number of colleges offering this stream in undergraduate studies leaves a chasm to be filled promptly in near future. Although the platform set in India regarding industries at present gives a kick start for employment and research opportunities in Industrial Engineering.
\end{abstract} in India.

Keywords: Industrial Engineering, technical education system, engineering education

\section{INTRODUCTION}

Industrial Engineering (IE) or Industrial Engineering \& Management (IEM) is the specialist branch of engineering that involves the improvement of the things, which led 
them to be better. Industrial engineers are focused on the reduction of production time, overall product production cost as well as improve the quality of the product and output efficiency. Industrial engineers are also responsible for the worker safety and health, productive working environment and complying with government regulations. They work to eliminate waste of time (worker time and machine time), money, materials, energy and other commodities. They engineer processes and systems that improve quality and productivity of the product and improve the production process. Industrial engineering is concerned with the development, improvement and implementation of integrated systems of people, money, knowledge, information, equipment, energy, materials, analysis and synthesis, as well as mathematical, physical and social sciences together with the principles and methods of engineering design to specify, predict and evaluate the results to be obtained from such systems or processes (Elsayed, 1999; Köksal \& Eğitman, 1998).

The term "industrial engineering" coined in the late 18th century, when it was only linked with the increase in efficiency and profit of the production plant. From Industrial Revolution till now, rapid development of machinery and power sources to run them provide the new challenges for the industrial engineers to optimize their use in the effective production of the product. Since an industrial engineer participates in each stage of the production, they are accountable for the upgrading (adding new tools or a new technology), expanding (enhancing the production of the same product, which is demanded in market in short time), halting (stopping the production of product or unit, which is going in loss), reconfiguring (optimizing the use of unit by configuration of unit again) existing production faculties and sub-faculties (Elsayed, 1999). Industrial engineers are also responsible for adding the new equipment and modifying the existing instruments, which can be used to meet the production of a product.

To maintain the industry standards, industrial engineers have basic working knowledge of multiple engineering fields as well as are familiar with the associated tools, material, equipment and operational process. According to the US Bureau of Labor Statistics (BLS), depending on their tasks, industrial engineers work both in offices and in the settings they are trying to improve. Most industrial engineering job has eligibility of undergraduate degree of industrial engineering or mechanical engineering having specialization of industrial engineering subject. A degree with the management is preferable in the higherlevel jobs in industry. Also, employment rate of the industrial engineers will grow five percent from the time period of 2017 to 2022 (BLS Report, 2013).

Since, industrial engineers possess knowledge of multiple fields, they can apply this science, mathematics and engineering methods in complex system integration. Industrial engineers use their skills to improve the production process by using the statistical data analysis, proper planning, execution of the plan, quality control of the product, operation management, personal communication in different levels for issue, computer simulation etc. (Salvendy, 2001). Beside these, industrial engineers also analyze and design the working faculties of the production unit, working group workspace, material handling, information system, resource allocation, worker safety, quality assurance etc. (Strong, Sharonb \& Jamshed, 2004).

India is the second largest county in the world by population with the biggest population of young people in the world and the seventh largest country in the world by area. India has the largest number of technical institutes and engineering students in the world (Bajpai \& Khare, 2015). After the independence of India, industrialization process started through Public Sector Units (PSU), which is set up Indian government and private 
sector companies set their manufacturing units to fulfill the demand generated by locals, manufacturing sector got accelerated and there was a great demand for skilled engineers across the industry (Khare, Chatterjee \& Bajpai, 2014).

Present paper is divided into three major parts in which first part has dedicated to the status of industrial engineering education in India at five different stages from diploma, undergraduate, postgraduate, doctoral to post-doctoral level, then future scope of industrial engineering in different production industries with the employment of industrial engineering engineers or other engineering graduate students (mechanical, production, mechatronics, manufacturing, metallurgical) having industrial engineering background and at the end of paper, a conclusion of industrial engineering education in India with a brief comparison with the other countries across the globe.

\section{THE AIM OF THE STUDY}

The aim is to give a complete survey of the industrial engineering education in India. Since industries generate the employment for citizens of any country, so it is necessary to have an appropriate skill for the job. For skill development, academic institutes are needed. The authors outline the following objectives of the present manuscript, which is follows here: 1) to give the complete review of the engineering education from diploma level to postdoctoral level in India; 2) to outline the effort of India Government specific to industrial engineering; 3) to give the comparative overview of the industrial engineering with other countries.

\section{THEORETICAL FRAMEWORK AND RESERCH METHODS}

Theoretical framework of present research consists of current data on engineering education system of India, specific to industrial engineering. A similar type of research had been carried out in the multiple fields, which are control engineering, production engineering, mechatronics engineering \& manufacturing engineering.

Indian technical education system is more than 200-year-old, when they laid off the first technical institute at Chennai as survey school in 1794. From then till today, there are 4354 diploma institutions (polytechnics) offering diploma in 60 major disciplines and 5850 technical institutions offering (including technical universities) undergraduate degree in about 45 major engineering disciplines, post graduate degree in more than 200 engineering specialization, doctoral degree in almost each area of technical core or sub core areas of the technical disciplines \& postdoctoral degree in the specific sub-areas (industry-oriented) of the industrial engineering at premium technical institutes of India (Banerjee \& Muley, 2007). The first engineering college was established in the India in 1847 for the training of Civil Engineers at Roorkee named as College of Civil Engineering (1847-1853), later on, name changed to Thomason College of Civil Engineering (1853-1948). After the independence of India, it became University of Roorkee (1948-2001) and currently it is known as Indian Institute of Technology, Roorkee. Indian Institute of Science (IISc), Indian Institute of Technology (IITs) and National Institute of Technology (NITs) are top technical institutions in India which are providing the education in engineering (Agarwal, 2007).

The industry is the base of any country economy, whether it is products of daily needs, machinery, computer related hardware or system etc., computer hardware, electronics product, metal associated work etc (Khare, Bajpai \& Bharati, 2015). Industrial Engineering is offered as a mandatory subject for the mechanical engineering and associated engineering curriculum. Operation Research \& Project Management is also offered as a mandatory subject for mechanical engineering and associated engineering curriculum (Dixit et al., 2017). 
Duration of diploma degree engineering course is six semesters (three year course), undergraduate degree course (B. Tech or B.E. or BSc Eng.) course is eight semester (four year course), dual degree course (B. Tech or B.E. with M. Tech or B. Tech or B.E. with M.B.A.) is ten semester (five year course) and postgraduate degree course (M. Tech or M.E.) is four semester (two year course) for full-time postgraduate course and six semesters (three year course) for part-time or evening postgraduate course (Khare, Chatterjee, Bajpai \& Bharati, 2016). Duration of the doctoral degree program is normally three-year but it can be extended up to six years according to the need of the research topic. Students have to do the two-semester course work, which includes two to four subjects according to their research topic, which gets approved by their supervisor. Postdoctoral program is of two years duration but it can be extended next a year according to the project requirements (Khare, Chatterjee \& Bajpai, 2014).

In Europe, North America and another part of the world, Industrial Engineering and Production Engineering are taught separately as an independent engineering disciplined, but in India, it is taught as a common postgraduate course in the name of Production Engineering or Industrial Engineering under the mechanical Engineering (Strong, Sharonb \& Jamshed, 2004; Khare, Chatterjee, Bajpai \& Bharati, 2016).

Diploma courses in industrial engineering are not offered but it is offered with the production engineering in the name of "Production and Industrial Engineering" by few polytechnics across India. AICTE (All India Council for Technical Education) has approved and given a model for diploma level engineering courses. In diploma, first-year course curriculum is common to the diploma courses. It has major subjects are Applied Physics, Applied Mathematics, Applied Chemistry, English, Engineering Drawing \& Information Technology (introductory level). The second-year course curriculum is similar to mechanical engineering and it is associated diploma courses in which major subjects are Applied Mechanics, Workshop Technology, Mechanical Engineering Drawing, Hydraulics and Pneumatics, Strength of Materials, Thermodynamics and Strength of Materials. Final year (third year) course curriculum has specialization associated subjects in which major subjects are Production, Planning and Control, Industrial Metrology and Quality Control, Industrial Safety and Maintenance, Industrial Engineering and Machines, and Automation. One subject associated with industrial engineering has been taught in the final year mechanical engineering diploma.

At undergraduate level (B.E. or B. Tech or BSc Eng.), there are about 10-14 core subjects \& 2-4 elective subjects options which are directly associated with industrial engineering, rest of them are related mechanical engineering, mathematics and management science (Khare, Chatterjee \& Bajpai, 2014). Major core theory subjects are operational research, production design and process planning, product planning, quality control, supply chain management, product development, heuristic methods and quality engineering. Elective courses are more associated with the project areas in which students are working. Major subject offering under this category is interdisciplinary courses, which can be taken by the production engineering and mechanical engineering students. UG curriculum includes a major project, which is done in the final year (both semester) on the field of Ergonomics and Work System Design, E-Procurement and Reverse Auction, Information Systems, Layout, Logistics, Operations Research, Optimization in business decision, Quality Engineering and Management, Project Management, Safety Engineering and Management, System Dynamics \& Work Study etc.

The UG course of industrial engineering at Indian Institute of Technology, Kharagpur has laid out a proper format, which includes appropriate courses from mechanical engineering, mathematics, management and other departments. 
Indian Institution of Industrial Engineering (founded in 1957, head office in Mumbai) is an institute for propagating the profession of Industrial Engineering and also generating the skill industrial engineers in India. This Institution has 27 chapters all across India. Indian Institution of Industrial Engineering (IIIE) conducts a Graduateship Examination as an external examination for enabling candidates of other engineering background (diploma in other engineering braches), to qualify for Graduate Membership of the institution. The graduateship examination conducted by the institution is recognized by the Central Government of India as identical to bachelor's degree in industrial engineering from any technical campus in India.

At the postgraduate level industrial engineering is offered under the specialization Industrial Technology, Industrial Engineering and Management (IIT Kharagpur), Industrial Engineering and Operations Research (IIT Bombay), Industrial and Management Engineering (IIT Kanpur), Production \& Industrial Systems Engineering, Industrial Mathematics and Informatics (IIT Roorkee), Industrial Engineering, Industrial Automation (IIT Indore), Industrial and Production Engineering (NIT Kurukshetra), Industrial Engineering (NIT Nagpur), Industrial Engineering and Management (NIT Raipur) and Industrial Design (NIT Rourkela). IIT Kharagpur offers a dual degree (B. Tech with M. Tech; five-year course) in industrial engineering. Postgraduate level industrial engineering is offered under the specialization.

Major theoretical topics studied under postgraduate degree course include computational methods in engineering, tooling for manufacturing, flexible manufacturing systems, modeling of manufacturing processes, manufacturing management, manufacturing of non-metallic products, rapid manufacturing, lasers in manufacturing, design for manufacture, intelligent manufacturing systems, sustainable manufacturing etc. In final semester, the student has to defend his/her master's thesis before an external examiner (specialization to the thesis) from another institution in India. Master of Science (M.S.) course in Industrial Engineering specialization is offer at the IIT Kharagpur.

National Institute of Industrial Engineering (NITIE), Mumbai is one of the most prestigious and oldest institutions dedicated solely to the studies of Industrial Engineering. It was set up by the Central Government of India in 1963 with the assistance of United Nations Development Program (UNDP) through the International Labor Organization (ILO). Courses such as Postgraduate Diploma in Industrial Engineering (PGDIE), Postgraduate Diploma in Industrial Management (PGDIM), Postgraduate Diploma in Industrial Safety and Environmental Management (PGDISEM) are some of the courses available in it. It also offers Doctoral Fellowship Program recognized by Ministry of HRD, central government of India as equivalent to $\mathrm{PhD}$ of any Indian University.

Decision Support Systems, E-Procurement, Ergonomics, Information Systems, Inventory Control, Layout, Logistics, Operations Management, Operations Research, Project Management, Reverse Auction, Strategic Management, Supply Chain Management, System Dynamics, System Engineering and Work Study are the major field of Industrial Engineering in which faculty and research in India work. At the doctoral level, students deals with theoretical and practical problem analysis for their doctoral thesis. Some research projects funded by funding agency (Government agencies and Private organizations) may form a part of their research work.

Postdoctoral level research in Industrial Engineering is offered by top technical institutions in India by their industrial engineering or mechanical engineering department.

Due to its importance, many courses took by students during the undergraduate course of industrial engineering are same as those took by mechanical, production, mechatronics 
or manufacturing engineering, undergraduate students. Singiresu S. Rao, M. V. Gandhi, Balasubramanian Muralikrishnan, Jayaraman Raja, J. K. Sharma, Sunil Chopra, Siddhartha Ray, Dileep R. Sule, P. Rao, N. Tewari, T. K. Kundra are the major Indian authors whose books are adopted as a textbook in the different courses associated with the industrial engineering.

Various Computer Aided Manufacturing software such as NX CAM of Siemens and Delcam are most widely used for simulating industrial problems with utmost accuracy. There are numerous software such as MasterCAM, SolidCAM, CATIA etc. Some open source CAM software are OpenSCAM, Probotix CNC software, Wings 3D, Blender etc.

Indian Government has taken many initiatives to enhance teaching and learning through the online web medium. Indian Government has developed virtual labs, online videos lecture database through National Program for Technology Enhanced Learning (NPTEL) (Krishnan, 2009) and online theses management system Shodhaganga (Vishwakarma, Maurya \& Prarshar, 2013). Virtual labs are developed with the partnership of technical institutions \& Ministry of Human Resource Development (MHRD). Some labs such as metal forming lab, general purpose production shop simulation lab, laser based flow diagnostics laboratory, etc. have been already developed which is associated with the students of industrial engineering. Some labs are still in development phase (Ray, 2012). NPTEL program gives the students an opportunity to learn course from the faculties of the premier institutes of the country. Those students, who participate in these online series, are asked to take a test and are awarded a certificate on qualifying the test. The duration of these online courses is around 40-50 hours. Some small duration courses are also offered nowadays of such duration as 10 hours, 20 hours and 40 hours. An open source repository provides lectures of the faculties that students can access through online, which is completely free of cost. Students can also clear their doubts in some on-going courses. Indian Governments also develop an Android Application of NPTEL for the convenient of the student. Shodhganga is an online space for research scholars (from any country in the world) to access the research work ongoing in Indian universities \& scholars. They can also submit their doctoral theses (after defense through their campus) and make it available to the entire research community in open access space throughout the globe. This online repository is able to index, store, disseminate and preserve ETDs (Electronic Theses and Dissertations) (Vishwakarma, Maurya \& Prarshar, 2013). There is a program called "Text Book Companion" in which the students are asked to solve the standard books related to manufacturing or industrial engineering and to code the results so that the solutions can be visualized by the students. The solutions are usually coded in SciLab. Upon successful completion of the assigned book to the students they are rewarded both with a certificate as well as a cash prize (Bhattacharya, 2008 \& Banerjee \& Muley, 2007).

\section{RESULTS}

Only few premium technical institutes in India have departments on Industrial Engineering or Production Engineering. IIT Kharagpur has a dedicated department on Industrial Engineering, which offers degree courses (B. Tech and M. Tech) as well as DualDegree courses (B. Tech with M. Tech and B. Tech with MBA). This institute also offers Doctoral and Postdoctoral degree courses. In present 5 out of 23 IIT's offer courses in Industrial Engineering as shown in Fig. 1 and Fig. 3 whereas in NIT's the count is 17 out of 31 represented in Fig. 2 and Fig. 4. Indian Institution of Industrial Engineering offers MSc in industrial engineering and should also initiate some short term professional courses in Industrial Engineering. 


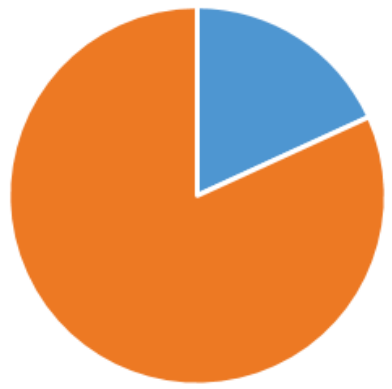

- IIT offering Industrial in UG

- IIT not offering Industrial in UG

Fig. 1. Industrial Engineering (UG) at IITs

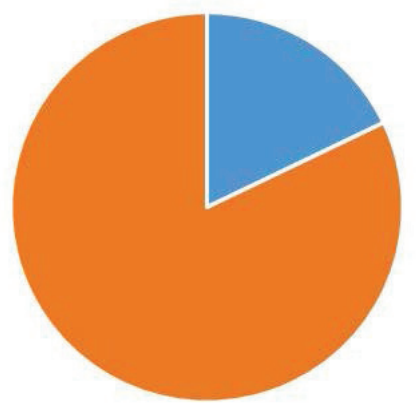

- IIT offering PG in Industrial

- IIT not offering PG in Industrial

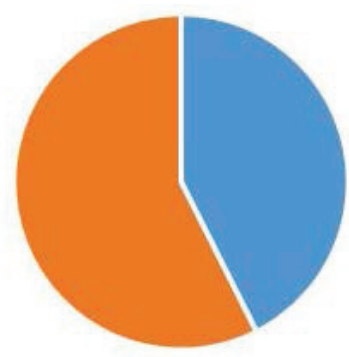

- NIT offering Industrial in UG

- NIT not offering Industrial in UG

Fig. 2. Industrial Engineering (UG) at NITs

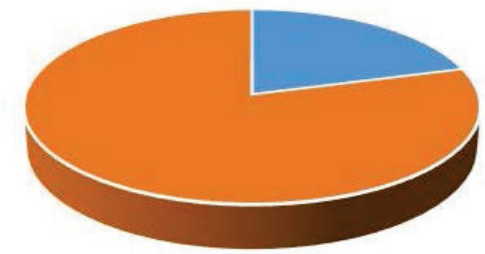

$$
\begin{aligned}
& \text { - NIT offering PG in Industrial } \\
& \text { - NIT not offering PG in Industrial }
\end{aligned}
$$

Fig. 4. Industrial Engineering (PG) at NITs

Fig. 3. Industrial Engineering (PG) at IITs

Engineering is the base for any type of industry. Engineers with a bachelor's degree in manufacturing or mechanical engineering are more likely to find their place in production firms both private and government sectors. As per their curriculum, they are most eligible for private production units, railways, armed forces and PSUs. Usually managerial or supervisory where critical decision-making skill is needed for the smooth production and high performance of the industry. Those who have a doctoral degree in manufacturing or industrial engineering are usually found taking a decision at the top levels of the organization or management. Scholars with a doctoral degree or above can easily find their ways in technical institutions across the globe. Usually, the graduates obtain the jobs in industry manufacturing engineer, operations analyst, industrial managers, management engineer, quality control technician, process engineers, quality engineers etc. Besides these, industrial engineers are also eligible for the certain jobs of mechanical engineers in government own companies including railways, Engineering Services Examination (ESE) and automobile sector are major (Khare, Chatterjee, Bajpai \& Bharati, 2016). 
Central Manufacturing Technology Institute (CMTI) is a registered Government of India Society, an autonomous institution under the administrative control of the ministry of commerce and industry (MoCI), which offers one year (two semesters) postgraduate diploma in advanced manufacturing technology (PGDAMT) in collaboration with Karunya University, Coimbatore, which is very beneficial for the industries as modern ways of manufacturing are extremely efficient and power saving which ultimately increases the profit of the organization. This course has the objective of making fresh engineers industry ready. This course trains an individual on typical manufacturing industry processes, advanced technologies, live applied research projects and industrial visits (Khare, Chatterjee, Bajpai \& Bharati, 2016)

A recent initiative of Indian government "Make In India" will help industrial engineers as the Indian government is inviting the manufacturing firms to open their manufacturing plants in India for production (Seal \& Shubhasree, 2015). This will generate the jobs for the candidates having an engineering degree in industrial engineering (Rajan, 2015; Biswas, 2016).

\section{CONCLUSIONS}

We have used widely accepted QS university ratings for shortlisting the universities to compare of industrial engineering education status in top universities of BRICS countries (Quacquarelli Symonds, 2017). Tsinghua University, China tops the chart of BRICS most prestigious nation, offers a bachelor's program in Industrial Engineering. It has many applications based research centers focusing on computer integrated manufacturing, numeric controlled manufacturing, automated manufacturing and CAD. Shanghai Jiao Tong University has a department of Industrial Engineering in China. Other top five universities in China do not have separate departments for manufacturing related courses. Bauman Moscow State Technical University of Russia has a program in Industrial engineering. Other technical campuses in Russia have higher degree program associated with the industrial engineering. The University of Sao Paulo, Brazil offers many graduate programs including industrial engineering under the aegis of Department of Materials and Manufacturing Engineering and Department of Production Engineering. The Brazilian government has provided a vision for education prioritizing on science and technology which reflects in their curriculum. Industrial Engineering also finds its place in the curriculum of various other courses in several different universities.

When compared to India, Brazil and South Africa have a better laid out plan for expansion of industrial engineering courses. While surprisingly Russia has merely a number of colleges focusing on industrial engineering. China stands at par with India with respect to industrial engineering education curriculum .

Industrial Engineering plays a pivotal role in the field of engineering for the proper development of industries in any nation. Indian government's initiatives in laying the framework of the industries for those commodities, which India is purchasing from the other parts of the world since independence is praiseworthy. These production plants across the country will see the advantage in the manufacturing and production engineering. Present scenario of industrial engineering education seems in its premature stages in India. With a mere number of colleges offering this stream in undergraduate studies leaves a chasm to be filled promptly in near future. Although the platform set in India regarding industries at present gives a kick start for employment and research opportunities in Industrial Engineering.

\section{REFERENCES}

1. Agarwal, P. (2007). Higher education in India: growth, concerns and change agenda. Higher Education Quarterly, 61 (2), 197-207. 
2. Bajpai, S., \& Khare, S. (2015). Mechatronics engineering education in India. Comparative Professional Pedagogy, 5 (4), 73-79.

3. Banerjee, R., \& Muley, V. P. (2007). Engineering education in India. Report to Energy Systems Engineering, IIT Bombay, sponsored by Observer Research Foundation, September, 14.

4. Bhattacharya, B. (2008). Engineering education in India - the role of ICT. Innovations in education and teaching International, 45 (2), 93-101.

5. BLS Report (2013). Employment Projections - 2012-2022. Retrieved from https://www.bls.gov/news.release/archives/ecopro_12192013.pdf.

6. Biswas, R. (2016). Can India become Asia's next growth engine? In R. Biswas (Ed.), Asian Megatrends (pp. 114-128). London: Palgrave Macmillan.

7. Dixit, U. S., Hazarika, M., \& Davim, J. P. (2017). A brief history of mechanical engineering. Springer.

8. Elsayed, E. A. (1999). Industrial engineering education: a perspective. European journal of engineering education, 24 (4), 415-421.

9. Khare, S., Bajpai, S., \& Bharati, P. K. (2015). Production engineering education in India. Management and Production Engineering Review, 6 (1), 21-25.

10. Khare, S., Chatterjee, A., Bajpai, S., \& Bharati, P. K. (2016). Manufacturing engineering education in India. Management and Production Engineering Review, 7 (1), $40-44$.

11. Khare, S., Chowdhry, S., \& Bajpai, S. (2014). Control engineering education in India. Power, Control and Embedded Systems (ICPCES), 2014 International Conference on IEEE. Allahabad: Department of Electrical Engineering, Motilal Nehru National Institute of Technology.

12. Krishnan, M. S. (2009). NPTEL: A programme for free online and open engineering and science education. International Workshop on Technology for Education, 2009 (T4E'09). Bangalore.

13. Köksal, G. \& Eğitman, A. (1998). Planning and design of industrial engineering education quality. Computers \& industrial engineering, 35 (3-4), 639-642.

14. Quacquarelli Symonds. (n/a). Retrieved from http://www.qs.com.

15. Rajan, R. (2015). Make in India, largely for India. Indian Journal of Industrial Relations, 50 (3), 361-373.

16. Ray, S., Koshy, N. R., Diwakar, S., Nair, B., \& Srivastava, S. (2012). Sakshat Labs: India's virtual proteomics initiative. PLoS biology, 10 (7), 1-5, e1001353.

17. Salvendy, G. (Ed.). (2001). Handbook of industrial engineering: technology and operations management. New York; Chichester; Weinheim; Brisbane; Singapore; Toronto: John Wiley \& Sons.

18. Seal, J. K., \& Bhadra, S. (2015). Make in India: employment and foreign direct investment. The MA Journal, 50 (7), 67-73.

19. Strong, D. M., Johnson, S. A., \& Mistry, J. J. (2004). Integrating enterprise decision-making modules into undergraduate management and industrial engineering curricula. Journal of Information Systems Education, 15 (3), 301-313.

20. Vishwakarma, M. L., Maurya, S. L., \& Parashar, V. (2013). Shodhaganganational reservoir of the Indian electronic theses \& dissertation. International Journal of Emerging Technology and Advanced Engineering, 3 (5), 172-177. 